\section{INPATIENT ENDOSCOPY: REFERRAL APPROPRIATENESS AND EFFICIENCY OF SERVICE PROVISION}

W J Tee, G Chan, Z Ahmed, O Jagun, S Brady, M Buckley, S Sarwar, C Smyth, R Farrell Gastroenterology Department, Connolly Hospital, Blanchardstown, Dublin, Ireland; RCSI, Dublin, Ireland

\subsection{6/gutjnl-2013-305143.40}

Introduction There is an increasing burden on endoscopy units in Ireland to reduce waiting lists and to provide an efficient service. This is compounded by the introduction of the colorectal screening programme, the initiation of the medical assessment unit and the hiring freeze on endoscopy personnel. Therefore, it is essential that all inpatient endoscopy referral indications are appropriate and that provision is made to ensure that requests are dealt with efficiently, without delaying patient discharge.

Aims/Background To evaluate the appropriateness of inpatient endoscopy requests as well as to assess the efficiency of inpatient endoscopy service provision.

Method All inpatient endoscopy requests were included prospectively from 20th November 2012 to 21st January 2013. Appropriateness of referral indication was compared against the American Society of Gastroenterology guidelines as well as criteria pre-determined by gastroenterology consultants or registrars in the department. Efficiency of service was evaluated by reviewing the significance of endoscopic findings and if the endoscopic procedures facilitated earlier discharge from hospital.

Results 30 requests for inpatient endoscopy were received over the study period, mean age $68.3 \pm 13.4$ years. This accounted for a total of $5.7 \%$ endoscopic procedures performed during the period (30/527). $27 / 30(90.0 \%)$ of the requests were thought to be appropriate. $2 / 30(6.7 \%)$ requests were cancelled by the gastroenterology team due to poor patient clinical status. $1 / 30$ patient was cancelled due to poor indication as the patient had

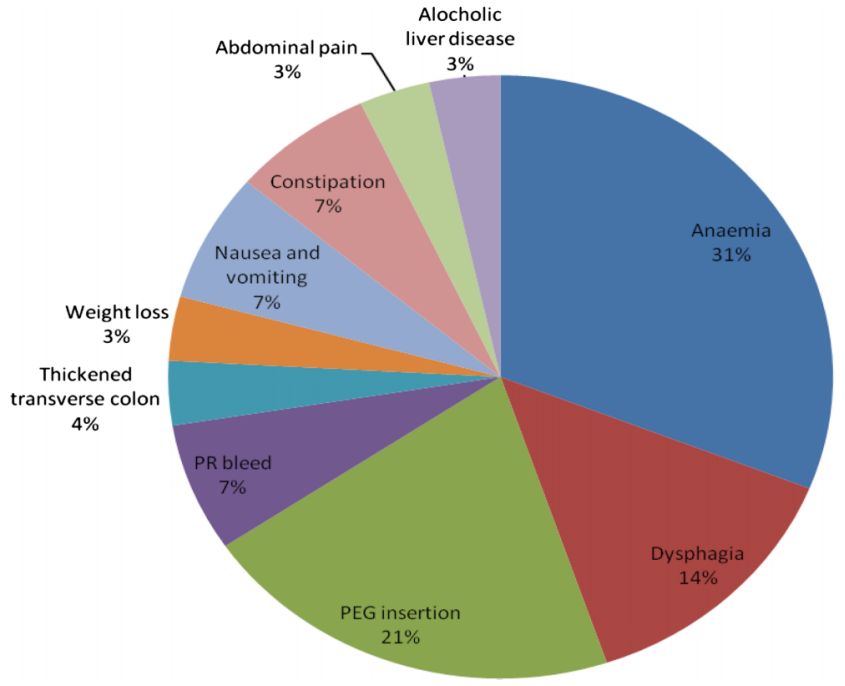

Figure 1 Chart demonstrating the indications for inpatient endoscopy requests). Almost all referrals originated from medical teams (25/27, $92.6 \%)$.

normocytic anaemia secondary to chronic renal failure. There were $11(40.7 \%)$ requests for oesophagogastroduedenoscopy (OGD), 3 (11.1\%) for colonoscopy, 5(18.5\%) for OGD and colonoscopy, $6(22.2 \%)$ for percutaneous endoscopic gastrostomy (PEG) tube insertion and 2 (7.4\%) for sigmoidoscopy. Of the appropriate referrals, the most common indications were microcytic anaemia in $8 / 27(29.6 \%)$ patients, PEG insertion in $6(22.2 \%)$ patients and dysphagia in $4(14.8 \%)$ patients

Conclusion Almost all of the inpatient endoscopy requests were thought to be appropriate, confirming that hospital doctors have good awareness for referral indications. The endoscopy service provided in our hospital is very efficient with more than half of patients undergoing their procedures within a day of referral.

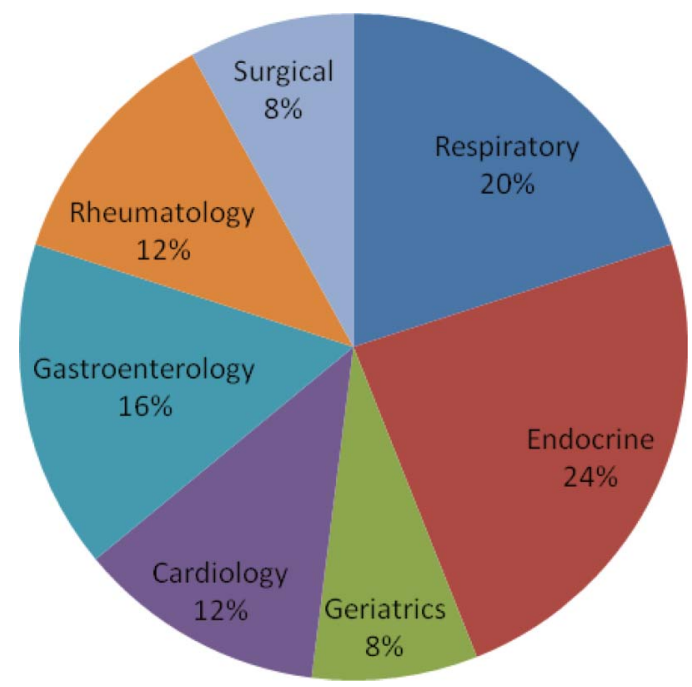

Figure 2 Chart demonstrating source of inpatient endoscopy referral). $13(48.1 \%)$ patients underwent endoscopy within one day of referral and only $5(18.5 \%)$ waited for three or more working days. 


\section{Abstracts}

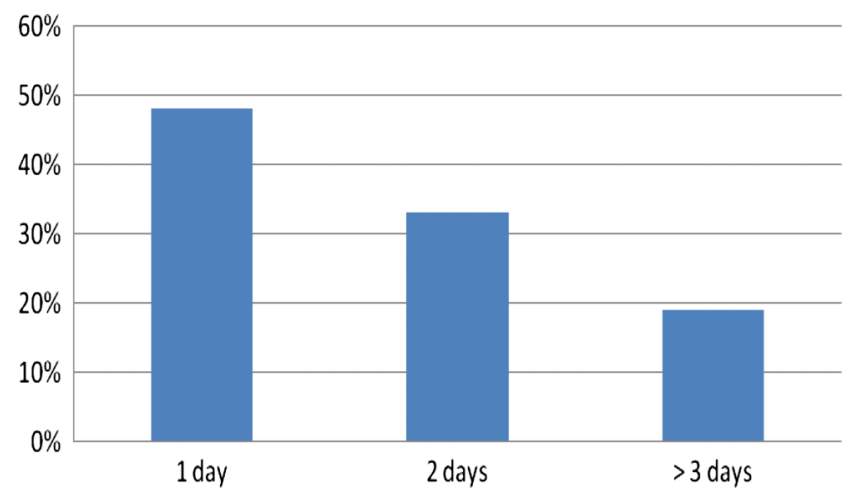

Figure 3 Chart demonstrating the waiting times for inpatient endoscopy). Endoscopy yielded significant findings in 14 (51.9\%)

patients. Early endoscopy facilitated more rapid discharge from hospital in $9(33.3 \%)$ of patients. 


\section{Corrections}

W J Tee, G Chan, Z Ahmed, et al. 40: INPATIENT ENDOSCOPY: REFERRAL APPROPRIATENESS AND EFFICIENCY OF SERVICE PROVISION. Gut 2013;62(Suppl 2): A17-A18. doi:10.1136/gutjnl-2013-305143.40. The author list for this abstract should read:

Chan G, Tee W J, Brady S, Ahmed Z, Backley S, Jagun O, Martin H, Buckley M, Sarwar S, Smyth C, Farrell R.

Gut 2013;62:1269. doi:10.1136/gutjnl-2013-305143.40corr1 